\title{
No Axillary Lymph Node Dissection in Breast Cancer Patients with Sentinel Lymph Node Micrometastasis
}

\author{
Marco Gipponi $^{{ }^{*}}$, Piero Fregatti ${ }^{1}$, Federica Murelli ${ }^{1}$, Paolo Meszaros ${ }^{1}$, Francesca Depaoli ${ }^{1}$, \\ Cecilia Margarino ${ }^{1}$, Paola Baccini ${ }^{2}$, Marina Gualco ${ }^{2}$, Daniele Friedman ${ }^{1}$ \\ ${ }^{1}$ Breast Unit, IRCCS “San Martino-IST”, Genoa, Italy \\ ${ }^{2}$ Pathologic Unit, IRCCS “San Martino-IST”, Genoa, Italy \\ Email: *marco.gipponi@hsanmartino.it
}

Received November 19, 2013; revised December 15, 2013; accepted December 23, 2013

Copyright (c) 2014 Marco Gipponi et al. This is an open access article distributed under the Creative Commons Attribution License, which permits unrestricted use, distribution, and reproduction in any medium, provided the original work is properly cited. In accordance of the Creative Commons Attribution License all Copyrights (c) 2014 are reserved for SCIRP and the owner of the intellectual property Marco Gipponi et al. All Copyright (C) 2014 are guarded by law and by SCIRP as a guardian.

\begin{abstract}
Follow-up data of a series of 75 breast cancer patients with sentinel node (SN) micrometastases only (between 0.2 and $2 \mathrm{~mm}$ ) and favorable histopathological features of the primary tumor (well-differentiated, T1 tumors without lymphovascular invasion) who refused completion axillary lymph node dissection (ALND) or who were unsuitable for surgery were assessed in order to detect the rate of axillary recurrence after an adjuvant chemoand/or hormonal adjuvant treatment was given. The great majority of patients (81.3\%) did not undergo ALND due to the existence of favorable histopathologic factors while the rest were equally distributed among over 75-year-old women $(\mathbf{1 0 . 6 \% )}$ ) and patients at a high surgical risk due to comorbid conditions $(\mathbf{9 . 3 \% )}$. Sixty-six patients $(\mathbf{8 8} \%)$ underwent conservative treatment (lumpectomy followed by adjuvant breast radiotherapy) while the remaining nine patients $(12 \%)$ had total mastectomy; 72 out of 75 patients $(96 \%)$ received some forms of adjuvant chemo- and/or hormone-therapy. After a median follow-up of 38 months (range 12 - 84 months), nine out of 75 patients $(12 \%)$ had a disease relapse, only one of them $(1.3 \%)$ being affected by an axillary recurrence in the untreated axilla three years after primary surgery. On these grounds, completion ALND could be safely omitted in patients with SN micrometastasis and favorable histopathological characteristics of the primary neoplasm due to the very low rate of axillary recurrence with no detrimental effect on survival.
\end{abstract}

\section{KEYWORDS}

\section{Sentinel Lymph Node; Axillary Lymph Node Dissection; Breast Cancer}

\section{Introduction}

Sentinel lymph node (SN) biopsy has become the standard of care as staging procedure in clinically node-negative breast cancer patients in order to achieve a more selective approach to completion axillary lymph node dissection (ALND) [1-3]. In many instances, however, especially in the case of SN micrometastasis, the rate of non-SN involvement after completion ALND is rather low with an observed pooled proportion of $20.2 \%$, as reported in the meta-analysis by Cserni et al. [4]. These figures may be even lower in patients with more favorable histopatological features, such as those with welldifferentiated T1 tumors $(<2 \mathrm{~cm})$ without lympho-vas-

${ }^{*}$ Corresponding author. cular invasion (LVI) [5,6]. Although ALND provides additional prognostic information such as the number of involved lymph nodes, which may be useful only for the planning of post-operative radiotherapy, and may decrease the rate of regional recurrences, its impact on survival seems negligible coupled with an increased morbidity as compared to SN biopsy alone [7-12].

For these reasons, the therapeutic benefit of a completing ALND has gradually lost much of its interest. Actually, ALND may be considered optional in the following clinical setting: 1) patients with 1 - 2 tumor-positive SN and favorable histopathological features, for whom the planning of adjuvant systemic therapy is unlikely to be affected; 2) elderly patients; and 3) patients with serious comorbid factors [13,14]. 
In the present study, we revised the follow-up of a series of breast patients with $\mathrm{SN}$ micrometastasis and favorable histopathological features of the primary tumor who refused completion ALND after an informed consent was given or who were unsuitable for surgery due to comorbid conditions, in order to assess the rate of axillary recurrence after an adjuvant chemo- and/or hormonal adjuvant post-operative treatment.

\section{Patients and Methods}

Between January 2005 and December 2012, 1743 patients with early-stage (clinical $\mathrm{T}_{1-2} \mathrm{~N}_{0} \mathrm{M}_{0}$ ) breast cancer underwent SN biopsy as part of their standard treatment at the Breast Unit of the IRRCS "AziendaOspedalieraUniversitaria San Martino-IST" of Genoa. Clinical, histopathological, and follow-up data were collected into an institutional database; 75 patients with SN micrometastases only (between 0.2 and $2 \mathrm{~mm}$ ) who did not undergo ALND were retrospectively identified, and they represented the specific target of this study. SN micrometastases were usually detected at definitive histological examination. ALND was not performed due to patient's refusal of the operation after an informed consent was given about the existence of favorable histopathological features of the primary tumor (i.e., T1 breast cancer with Scarff-Bloom-Richardson (SBR) grade well (G1) or moderately differentiated (G2), and no lymphovascular (LVI) invasion); moreover, patients over 75 years of age or with comorbid conditions that would have seriously increased the operative risk were usually regarded as not eligible for ALND. All patients underwent an adjuvant systemic treatment according to national guidelines [15]. The study protocol was approved by the Ethic Committee of the Institute.

As regards the detection and histology of $\mathrm{SN}$, a standard procedure was adopted, as previously described [16]. Pathological staging was defined according to the International Union Against Cancer (UICC) TNM classifications of malignant tumors [17]. The following variables were retrospectively reviewed in the specific database: patients' characteristics (age at diagnosis, menopausal status), tumor features (tumor size, histological type, SBR grade, LVI, Ki-67 proliferative index, c-ERBB2 expression, hormonal expression), and adjuvant treatments (chemotherapy, endocrine therapy, post-operative radiotherapy). Follow-up data included the length of follow-up and the analysis of the pattern of failure.

\section{Results}

The characteristics of patients and the histopathological features of the primary tumor are reported in Table 1. Overall, 75 patients were included in the present analysis; the mean patient age was 68 years (range $=47-78, \mathrm{SD}=$
Table 1. Characteristics of the patients and breast tumor description.

\begin{tabular}{|c|c|c|}
\hline \multirow{2}{*}{ Characteristic } & \multicolumn{2}{|c|}{ Total patients $(\mathrm{n}=75)$} \\
\hline & No. & $\%$ \\
\hline \multicolumn{3}{|l|}{ Age at diagnosis, years } \\
\hline$<50$ & 17 & 22.6 \\
\hline $50-70$ & 25 & 33.3 \\
\hline$>70$ & 33 & 44.1 \\
\hline \multicolumn{3}{|l|}{ Menopausal status } \\
\hline Yes & 59 & 78.6 \\
\hline No & 16 & 21.4 \\
\hline \multicolumn{3}{|l|}{ Tumor size, mm } \\
\hline $1-20$ & 61 & 81.3 \\
\hline$>20$ & 14 & 18.7 \\
\hline \multicolumn{3}{|l|}{ Histological type } \\
\hline Non-lobular & 60 & 80.0 \\
\hline Lobular & 15 & 20.0 \\
\hline \multicolumn{3}{|l|}{ SBR grade } \\
\hline I & 37 & 49.3 \\
\hline II & 32 & 42.6 \\
\hline III & 6 & 8.1 \\
\hline \multicolumn{3}{|l|}{ LVI } \\
\hline No & 65 & 86.6 \\
\hline Yes & 10 & 13.4 \\
\hline \multicolumn{3}{|l|}{ Ki-67 proliferative index } \\
\hline$\leq 10 \%$ & 33 & 44.0 \\
\hline$>10 \%$ & 42 & 56.0 \\
\hline \multicolumn{3}{|l|}{ c-ERBB2 expression } \\
\hline Negative & 57 & 76.0 \\
\hline Positive (+) & 8 & 10.6 \\
\hline Highly positive $(++/+++)$ & 10 & 13.4 \\
\hline \multicolumn{3}{|l|}{ Hormonal expression } \\
\hline ER-positive/PgR-positive & 60 & 80.0 \\
\hline ER-negative/PgR-positive & - & - \\
\hline ER-positive/PgR-negative & 8 & 10.6 \\
\hline ER-negative/PgR-negative & 7 & 9.4 \\
\hline \multicolumn{3}{|l|}{ Adjuvant chemotherapy } \\
\hline Yes & 50 & 66.6 \\
\hline No & 25 & 33.4 \\
\hline \multicolumn{3}{|l|}{ Adjuvant endocrine therapy } \\
\hline Yes & 67 & 89.3 \\
\hline No & 8 & 10.7 \\
\hline \multicolumn{3}{|l|}{ Adjuvant radiotherapy } \\
\hline Yes & 66 & 88.0 \\
\hline No & 9 & 12.0 \\
\hline
\end{tabular}

ER, Estrogen receptor; PgR, Progesterone receptor; LVI, lymphovascular invasion; SBR, Scarff-Bloom-Richardson; c-ERBB2, HER-2/neu.

10.5 years). The mean size of the primary tumor was 12 $\mathrm{mm}$ (range $=6-24, \mathrm{SD}=4.5 \mathrm{~mm}$ ). The mean number of 
SN examined per patient was 1.6 (range $=1-3, \mathrm{SD}=$ 0.9 ). The great majority of patients ( 61 out of $75=81.3 \%$ ) did not undergo ALND due to the existence of favorable histopathologic factors (T1, and G1/G2, and no LVI), the remaining being equally distributed among over 75year-old patients ( 7 out of $75=9.3 \%$ ) and patients at high surgical risk due to comorbid conditions (7 out of $75=9.3 \%$ ). Sixty-six patients (88\%) underwent conservative treatment (lumpectomy followed by adjuvant breast radiotherapy) while the remaining nine patients (12\%) had total mastectomy; 72 out of 75 patients (96\%) received some form of adjuvant chemo- and/or hormonetherapy.

The median duration of follow-up was 38 months (range 12 - 84 months); follow-up was 2 - 5 years in 60 patients $(80 \%)$. Nine out of 75 patients $(12 \%)$ had a disease relapse (Table 2); one of them (1.3\%) had an axillary recurrence in the untreated axilla three years after primary surgery, and she underwent therapeutic ALND with an uneventful recovery thereafter.

\section{Discussion}

SN biopsy has substantially replaced ALND for the pathological staging of the axilla in patients with clinically node-negative breast cancer; this procedure has a more than satisfactory accuracy, thus allowing to reserve ALND in patients with tumor-positive SN only, with reduced overall postoperative morbidity and improved quality of life [1-3,18,19]. Noteworthy, in $38 \%$ to $67 \%$ of patients with tumor-positive SN undergoing completion ALND the only tumor-involved lymph node is just the SN; hence, most patients would not benefit at all from ALND [20-22]. This rate is likely to increase over time thanks to earlier diagnosis of breast cancer due to the widespread use of screening mammography, as the risk of axillary metastases is close to $10 \%$ in tumors of less than $1 \mathrm{~cm}[21,22]$. Noteworthy, in patients with SN micrometastasis the rate of tumor-positive nodes at completion ALND drops down to $0 \%$ and $2.8 \%$ when the tumor size is less than $1 \mathrm{~cm}$ and between 1 and $2 \mathrm{~cm}$, respectively $[23,24]$. Moreover, the selection of patients eligible for systemic adjuvant treatment is currently influenced by various patient- and tumor-related factors, such that axillary lymph node status, as well as the extent of lymph node involvement, no longer determines this decision analysis [25].

Overall, these figures are progressively limiting the need of performing a therapeutic ALND, according to current perspective on the natural history of breast cancer that would suggest the usefulness of ALND as for survival in clinically node-negative patients. Actually, the 25-year report of the randomized trial B-04 initiated in 1971 failed to show any survival advantage from removing occult positive nodes at the time of initial surgery
Table 2. Follow-up data.

\begin{tabular}{cll}
\hline Length of follow-up & No. & $\%$ \\
\hline 1 year & 8 & 10.6 \\
2 year & 10 & 13.4 \\
3 year & 18 & 24.0 \\
4 year & 22 & 29.3 \\
5 year & 10 & 13.4 \\
$>5$ year & 7 & 9.3 \\
\hline Failure & & \\
\hline No & 69 & 92.0 \\
Yes & 6 & 8.0 \\
\hline Site of first event & & \\
\hline Local & 1 & 1.3 \\
Local + regional nodes & 1 & 1.3 \\
Regional node recurrence & 1 & 1.3 \\
Contralateral breast & 2 & 2.6 \\
Distant & 4 & 5.3 \\
Total & 9 & 12.0 \\
\hline
\end{tabular}

[26]. Recently, the role of completion ALND in patients with a tumor-positive $\mathrm{SN}$ has been further challenged by the results of the American College of Surgeons Oncology Group (ACOSOG) Z0011 trial, confirming the excellent regional control of SN biopsy without ALND in selected patients with early-stage breast cancer $[8,9]$. For these reasons, ALND may be considered optional in the following clinical setting: 1) patients with 1 - 2 tumor-positive SN and favorable histopathological features, for whom the planning of adjuvant systemic therapy is unlikely to be affected; 2) elderly patients, and 3) patients with serious comorbid factors [13,14].

On these grounds, a series of patients with SN micrometastasis and favorable histopathological features of the primary tumor who refused completion ALND or unsuitable for surgery due to comorbid conditions were investigated in order to assess the rate of axillary recurrence and its consequence as for subsequent disease relapse. Notwithstanding the rather limited sample of patients due their selective accrual in this study, our findings confirm that the rate of axillary recurrence is very low $(1.3 \%)$, in agreement with previous report ranging from $1 \%$ to $3 \%$; mostly, no further recurrence occurred following a delayed therapeutic ALND [7,8,27,28]. Moreover, almost all patients underwent adjuvant chemo- and/or hormone-therapy so that the prognostic information supplied by completion ALND looks negligible in the treatment decision planning.

\section{Conclusion}

In our view, these results well match with existing literature data so that: 1) completion ALND could be safely omitted in patients with SN micrometastasis and favora- 
ble histopathological characteristics of the primary neoplasm; 2) its role should be further assessed in patients with more aggressive prognostic features and/or with SN macrometastasis, and 3) ALND should be reserved to clinically node-positive breast cancer patients or with axillary recurrence in an untreated axilla.

\section{REFERENCES}

[1] A. E. Giuliano, P. I. Haigh, M. B. Brennan, N. M. Hansen, M. C. Kelley, W. Ye, E. C. Glass and R. R. Turner, "Prospective Observational Study of Sentinel Lymphadenectomy without Further Axillary Dissection in Patients with Sentinel Node-Negative Breast Cancer,” Journal of Clinical Oncology, Vol. 18, No. 13, 2000, pp. 2553-2559.

[2] U. Veronesi, G. Paganelli, G. Viale, A. Luini, S. Zurrida, V. Galimberti, M. Intra, P. Veronesi, P. Maisonneuve, G. Gatti, G. Mazzarol, C. De Cicco, G. Manfredi and J. R. Fernández, "Sentinel-Lymph-Node Biopsy as a Staging Procedure in Breast Cancer: Update of a Randomize Controlled Study,” Lancet Oncology, Vol. 7, No. 12, 2006, pp. 983-990. http://dx.doi.org/10.1016/S1470-2045(06)70947-0

[3] G. Canavese, A. Catturich, C. Vecchio, D. Tomei, M. Gipponi, G. Villa, F. Carli, P. Bruzzi and B. Dozin, "Sentinel Node Biopsy Compared with Complete Axillary Dissection for Staging Early Breast Cancer with Clinically Negative Nodes: Results of Randomized Trial," Annals of Oncology, Vol. 20, No. 6, 2009, pp. 1001-1007. http://dx.doi.org/10.1093/annonc/mdn746

[4] G. Cserni, D. Gregori, F. Merletti, A. Sapino, M. P. Mano, A. Ponti, S. Sandrucci, B. Baltás and G. Bussolati, "Meta-Analysis of Non-Sentinel Node Metastases Associated with Micrometastatic Sentinel Nodes in Breast Cancer," British Journal of Surgery, Vol. 91, No. 10, 2004, pp. 12451252. http://dx.doi.org/10.1002/bjs.4725

[5] G. Houvenaeghel, C. Nos, S. Giard, H. Mignotte, B. Esterni, J. Jacquemier, M. Buttarelli, J. M. Classe, M. Cohen, P. Rouanet, F. Penault Llorca, P. Bonnier, F. Marchal, J. R. Garbay, J. Fraisse, P. Martel, E. Fondrinier, C. Tunon de Lara and J. F. Rodier, “A Nomogram Predictive of Non-Sentinel Lymph Node Involvement in Breast Cancer Patients with a Sentinel Lymph Node Micrometastasis,” EJSO, Vol. 35, No. 11, 2009, pp. 690-695. http://dx.doi.org/10.1016/j.ejso.2008.10.003

[6] M. Gipponi, G. Canavese, R. Lionetto, A. Catturich, C. Vecchio, A. Sapino, D. Friedman and F. Cafiero, "The Role of Axillary Lymph Node Dissection in Breast Cancer Patients with Sentinel Lymph Node Micrometastases," European Journal of Surgical Oncology, Vol. 32, No. 2, 2006, pp. 143-147. http://dx.doi.org/10.1016/j.ejso.2005.10.003

[7] K. Y. Bilimoria, D. J. Bentrem, N. M. Hansen, K. P. Bethke, A. W. Rademaker, C. Y. Ko, D. P. Winchester and D. J. Winchester, "Comparison of Sentinel Lymph Node Biopsy Alone and Completion Axillary Lymph Node Dissection for Node-Positive Breast Cancer,” Journal of Clinical Oncology, Vol. 27, No. 18, 2009, pp. 2946-2953. http://dx.doi.org/10.1200/JCO.2008.19.5750
[8] A. E. Giuliano, L. McCall, P. Beitsch, P. W. Whitworth, P. Blumencranz, A. M. Leitch, S. Saha, K. K. Hunt, M. Morrow and K. Ballman, "Locoregional Recurrence after Sentinel Lymph Node Dissection with or without Axillary Dissection in Patients with Sentinel Lymph Node Metastases: The American College of Surgeons Oncology Group Z0011 Randomized Trial,” Annals of Surgery, Vol. 252, No. 3, 2010, pp. 426-432.

[9] A. E. Giuliano, K. K. Hunt, K. V. Ballman, P. D. Beitsch, P. W. Whitworth, P. W. Blumencranz, A. M. Leitch, S. Saha, L. M. McCall and M. Morrow, "Axillary Dissection vs No Axillary Dissection in Women with Invasive Breast Cancer and Sentinel Node Metastasis: A Randomized Clinical Trial,” JAMA, Vol. 305, No. 6, 2011, pp. 569575. http://dx.doi.org/10.1001/jama.2011.90

[10] S. Arnaud, G. Houvenaeghel, V. Moutardier, M. Butarelli, M. Martino, A. Tallet, A. C. Braud, J. Jacquemier, C. JulianReynier and I. Brenot-Rossi, "Patients' and Surgeons' Perspectives on Axillary Surgery for Breast Cancer," EJSO, Vol. 30, No. 7, 2004, pp. 735-743. http://dx.doi.org/10.1016/j.ejso.2004.05.007

[11] R. E. Mansel, L. Fallowfield, M. Kissin, A. Goyal, R. G. Newcombe, J. M. Dixon, C. Yiangou, K. Horgan, N. Bundred, I. Monypenny, D. England, M. Sibbering, T. I. Abdullah, L. Barr, U. Chetty, D. H. Sinnett, A. Fleissig, D. Clarke and P. J. Ell, "Randomized Multicenter Trial of Sentinel Node Biopsy versus Standard Axillary Treatment in Operable Breast Cancer: The ALMANAC Trial," Journal of the National Cancer Institute, Vol. 98, No. 9, 2006, pp. 599-609. http://dx.doi.org/10.1016/j.ejso.2004.05.007

[12] S. Latosinsky, K. Dabbs, F. Moffat, S. Latosinsky, K. Dabbs, F. Moffat and Canadian Association of General Surgeons and American College of Surgeons EvidenceBased Reviews in Surgery, "Quality-of-Life Outcomes with Sentinel Node Biopsy versus Standard Axillary Treatment in Patients with Operable Breast Cancer. Randomized Multicenter Trial of Sentinel Node Biopsy versus Standard Axillary Treatment in Operable Breast Cancer: The ALMANAC Trial," Canadian Journal of Surgery, Vol. 51, 2008, pp. 483-485.

[13] R. W. Carlson, D. C. Allred, B. O. Anderson, H. J. Burstein, W. B. Carter, S. B. Edge, J. K. Erban, W. B. Farrar, L. J. Goldstein, W. J. Gradishar, D. F. Hayes, C. A. Hudis, M. Jahanzeb, K. Kiel, B. M. Ljung, P. K. Marcom, I. A. Mayer, B. McCormick, L. M. Nabell, L. J. Pierce, E. C. Reed, M. L. Smith, G. Somlo, R. L. Theriault, N. S. Topham, J. H. Ward, E. P. Winer and A. C. Wolff, "NCCN Breast Cancer Clinical Practice Guidelines Panel: Breast Cancer. Clinical Practice Guidelines in Oncology,” Journal of the National Comprehensive Cancer Network, Vol. 7, 2009, pp. 122-192.

[14] H. S. Cody and N. Houssami, "Axillary Management in Breast Cancer: What's New for 2012?” Breast, Vol. 21, No. 3, 2012, pp. 411-415. http://dx.doi.org/10.1016/j.breast.2012.01.011

[15] AIOM, “Linee Guida Neoplasie Della Mammella,” 2006.

[16] M. Gipponi, C. Bassetti, G. Canavese, A. Catturich, C. Di Somma, C. Vecchio, G. Nicolò, F. Schenone, D. Tomei and F. Cafiero, "Sentinel Lymph Node as a New Marker 
for Therapeutic Planning in Breast Cancer Patients,” Journal of Surgical Oncology, Vol. 85, No. 3, 2004, pp. 102-111. http://dx.doi.org/10.1002/jso.20022

[17] F. L. Greene, D. L. Page, A. G. Fleming and C. M. Balch, Eds., “AJCC Cancer Staging Handbook," Springer, New York, 2002.

[18] U. Veronesi, G. Paganelli, G. Viale, A. Luini, S. Zurrida, V. Galimberti, M. Intra, P. Veronesi, C. Robertson, P. Maisonneuve, G. Renne, C. DeCicco, F. De Lucia and R. Gennari, "A Randomized Comparison of Sentinel-Node Biopsy with Routine Axillary Dissection in Breast Cancer,” New England Journal of Medicine, Vol. 349, No. 6, 2003, pp. 546-553. http://dx.doi.org/10.1056/NEJMoa012782

[19] R. E. Mansel, L. Fallowfield, M. Kissin, A. Goyal, R. G. Newcombe, J. M. Dixon, C. Yiangou, K. Horgan, N. Bundred, I. Monypenny, D. England, M. Sibbering, T. I. Abdullah, L. Barr, U. Chetty, D. H. Sinnett, A. Fleissig, D. Clarke and P. J. Ell, "Randomized Multicenter Trial of Sentinel Node Biopsy versus Standard Axillary Treatment in Operable Breast Cancer: The ALMANAC Trial,” Journal of the National Cancer Institute, Vol. 98, No. 9, 2006, pp. 599-609. http://dx.doi.org/10.1093/jnci/djj158

[20] A. E. Giuliano, "Sentinel Lymphadenectomy in Primary Breast Carcinoma: An Alternative to Routine Axillary Dissection,” Journal of Surgical Oncology, Vol. 62, No. 2, 1996, pp. 75-77.

http://dx.doi.org/10.1002/(SICI)1096-9098(199606)62:2< 75::AID-JSO1>3.0.CO;2-N

[21] P. J. Borgstein, R. Pijpers, E. F. Comans, P. J. van Dieast, R. P. Boom and S. Maijers, "Sentinel Lymph Node Biopsy in Breast Cancer: Guidelines and Pitfalls of Lymphoscintigraphy and Gamma Probe Detection,” Journal of the American College of Surgeons, Vol. 186, No. 3, 1998, pp. 275-283.

http://dx.doi.org/10.1016/S1072-7515(98)00011-8

[22] J. M. Barnwell, M. A. Arredondo, D. Kollmorgen, J. F. Gibbs, D. Lamonica, W. Carson, P. Zhang, J. Winston and S. B. Edge, "Sentinel Lymph Node Biopsy in Breast Cancer,” Annals of Surgical Oncology, Vol. 5, No. 2, 1998, pp. 126-130. http://dx.doi.org/10.1007/BF02303845

[23] A. Salem, "Sentinel Lymph Node Biopsy in Breast Cancer: A Comprehensive Literature Review," Journal of Surgical Education, Vol. 66, No. 5, 2009, pp. 267-275. http://dx.doi.org/10.1016/j.jsurg.2009.07.011

[24] D. J. Dabbs, M. Fung, D. Landsittel, K. McManus and R. Johnson, "Sentinel Lymph Node Micrometastasis as a Predictor of Axillary Tumor Burden,” Breast Journal, Vol. 10, No. 2, 2004, pp. 101-105. http://dx.doi.org/10.1111/j.1075-122X.2004.21280.x

[25] A. Goldhirsch, W. C. Wood, A. S. Coates, R. D. Gelber, B. Thürlimann and H.-J. Senn, "Strategies for SubtypesDealing with the Diversity of Breast Cancer: Highlights of the St. Gallen International Expert Consensus on the Primary Therapy of Early Breast Cancer 2011,” Annals of Oncology, Vol. 22, No. 8, 2011, pp. 1736-1747. http://dx.doi.org/10.1093/annonc/mdr304

[26] B. Fisher, S. Anderson, J. Bryant, R. G. Margolese, M. Deutsch, E. R. Fisher, J. H. Jeong and N. Wolmark, "Twenty-Year Follow-Up of a Randomized Trial Comparing Total Mastectomy, Lumpectomy, and Lumpectomy Plus Irradiation for the Treatment of Invasive Breast Cancer," New England Journal of Medicine, Vol. 347, No. 16, 2002, pp. 1233-1241. http://dx.doi.org/10.1056/NEJMoa022152

[27] International Brest Cancer Study Group, "Randomized trial Comparing Axillary Clearance versus No Axillary Clearance in Older Patients with Breast Cancer: First Results of International Breast Cancer Study Group Trial 10-93,” Journal of Clinical Oncology, Vol. 24, No. 3, 2006, pp. 337-344. http://dx.doi.org/10.1200/JCO.2005.01.5784

[28] M. Solá, J. A. Alberro, M. Fraile, P. Santesteban, M. Ramos, R. Fabregas, A. Moral, B. Ballester and S. Vidal, "Complete Axillary Lymph Node Dissection versus Clinical Follow-Up in Breast Cancer Patients with Sentinel Node Micrometastasis: Final Results from the Multicenter Clinical Trial AATRM 048/13/2000,” Annals of Surgical Oncology, Vol. 20, No. 1, 2013, pp. 120-127. http://dx.doi.org/10.1245/s10434-012-2569-y

\title{
List of Abbreviations (In Order of Comparison)
}

\author{
ALND: Axillary Lymph Node Dissection \\ SN: Sentinel Node \\ G: Grade \\ LVI: Lympho-Vascular Invasion \\ SD: Standard Deviation \\ ER: Estrogen Receptor \\ PgR: Progesterone Receptor \\ SBR: Scarff-Bloom-Richardson \\ c-ERBB2: HER-2/neu
}

